\title{
The impact of supervisor-nurse relationships, patient role clarity, and autonomy upon job satisfaction: Public and private sector nurses
}

\begin{abstract}
In the Australian healthcare sector, many changes in the public sector have affected nurse management and thereby, nurses. Yet it is unclear whether such efficiency measures, based on private sector business models, have impacted private sector nurses in similar ways. This paper examines four important issues for nurses: supervisor-subordinate relationships, perceptions of autonomy, role clarity in relation to patients and job satisfaction. The paper uses an embedded mixed methods research design to examine the four issues and then compares similarities and differences between public and private sector nurses. The findings suggest supervisor-subordinate relationships, patient role clarity and autonomy significantly predict job satisfaction. The private sector nurses reported more satisfaction than public sector nurses with their supervisor-subordinate relationships, plus higher perceptions of patient role clarity and autonomy, and hence, higher levels of job satisfaction. The findings raise questions about whether present management practices (especially public sector) optimise service delivery productivity.
\end{abstract}

Key words: Nursing, healthcare administration, nurse supervisors, job satisfaction, role clarity, autonomy, Australia. 
Nursing shortages continue to plague many countries, and the quality of nurses' working experiences is implicated in the attrition rates in nursing. This is an important issue because Australia is similar to other OECD countries in facing a shortage of skilled nurses (Kingma, 2001; OECD, 2005), relying on growing numbers of nurse migrants (Hawthorne 2001), with potential consequent transitional safety issues (Tregunno, Peters, Campbell \& Gordon, 2009).

Notably, an effective supervisor-subordinate relationship has been identified as the factor most likely to improve retention outcomes (Cohen, 2006). Supervisors are also important because nurses reporting dissatisfaction with management policies and practices have a $65 \%$ higher probability of leaving than nurses reporting satisfaction (Secombe \& Smith, 1997). However, the relative impacts that nurse supervisors have upon the job satisfaction of nurses in these different sectors remains under-researched. This is imperative because we know that job satisfaction is a predictor of nurse turnover (Cowin, 2002); hence this paper explores the impact of nurse management practices upon job satisfaction, plus the similarities and differences across the public and private hospital sectors.

One significant change in public sector hospitals is the recent implementation of management reforms. These reforms focused on replacing the public sector management model - relying on the power and professionalism of its professionals (nurses, doctors) to ration the distribution of public goods and services - with a private sector model focused on achieving outcomes (Ackroyd, Kirkpatrick \& Walker, 2007). The changes that occurred were numerous, including the need for nurses to learn new skills and attitudes (Winch, Creedy \& Chaboyer, 2002), and supervisors were given increased managerial autonomy, simultaneously reducing the power of their staff. According to Currie and Procter (2002), public sector managers have greater managerial power than their private sector counterparts. Nevertheless, they have not been given the training or resources to manage more effectively - hence subordinates tend not be motivated by their management practices (Hoque, Davis \& Humphries, 2004; Butterfield, 
Edwards \& Woodall, 2005). Further, Ferlie, Pettigrew, Ashburner and Fitzgerald (1996) argue that the autonomy of public sector employees has been curtailed, but not uniformly. Instead, the extent to which public sector nurses have experienced reduced autonomy appears to be dependent upon the ability of supervisors to 'mediat[e] the excesses of NPM [new public management]' (Ackroyd et al. 2007, p. 21). The supervisor-subordinate relationship therefore seems an important ingredient affecting how much autonomy public sector nurses have in addressing patients' needs.

A more client-centred approach was one important reform goal. However, Kelly (2005) argues this reform has been, at best, partially implemented. Researchers propose the reforms have led to more bureaucracy, with organisational activities geared towards efficiency and accountability goals, signifying that becoming more client-centred is a secondary focus (Behn, 2002; Kelly, 2005). They argue that the proof is in the activities and processes now undertaken by public sector employees. For example, becoming successfully client-centred involves performance indicators measuring client satisfaction levels, yet Kelly (2005) argues the public sector has been slow to embrace such measures. Hence, it seems the requirement for public sector employees to understand more than the technical needs and requirements of clients is a lower priority, with nurses, for example, potentially perceiving less clarity, support, autonomy and discretion to effectively service their patients' needs.

Such issues are important because past research suggests that the quality of supervision affects subordinates' access to information, resources and support (Gerstner \& Day, 1997), affecting their ability to meets the needs of clients (Johlke \& Duhan, 2000) as well as their perceptions of autonomy (Spreitzer, 1995; 1996; 2007). This paper therefore examines four important issues for nurses: supervisor-subordinate relationships, perceptions of role clarity in relation to the patient, perceptions of autonomy, and job satisfaction. Additionally, the similarities and differences across public and private sector nurses are compared. 


\section{Conceptual framework}

The association between supervisor-subordinate relationships, perceptions of patient role clarity, autonomy, and job satisfaction is examined using the Leader-Member Exchange (LMX) theoretical framework.

\section{Leader-Member Exchange Theory}

Leader-Member Exchange (LMX) theorises that supervisors manage employees differently, and consequently, differing outcomes occur for different groups of employees. Consequently, over time, the quality of 'social exchanges' leads to a diverse quality of relationships between supervisors and subordinates. Effective (high quality) LMX relationships are where employees experience a high level of mutual support, trust and respect (Gerstner \& Day, 1997), and where staff appear to be liked by their supervisors, irrespective of their performance (Graen \& Uhl-Bien, 1995). In addition, when high quality LMX relationships are present, supervisors provide employees with meaningful feedback and delegate decision-making and power to them (Wayne, Shore, \& Linden, 1997; Yrie, Hartman \& Galle, 2003). Such employees are also more likely to experience tangible benefits, such as promotions and bonuses, and intangible benefits, such as interesting work assignments or greater control over workloads (Yukl, 2006). For the supervisor, the benefits include expected increases in esteem and loyalty, plus the knowledge and satisfaction of influencing the behaviour of subordinates (Basu \& Green, 1995). Employees who perceive that their supervisors' support them are also more likely to reciprocate support for their supervisors (Wayne et al., 1997; Podsakoff, MacKenzie, Paine \& Bachrach, 2000).

Hence, using LMX theory, it is expected that the quality of the supervisor-subordinate relationship would influence nurses' ability to efficiently and effectively address patients' needs, by affecting their access to information, resources and support, particularly if patients present with complex symptoms. These very same factors are also expected to affect nurses' perceptions 
of autonomy, and in combination, their job satisfaction. In contrast, poor supervisor-subordinate relationships are likely to involve mixed messages from supervisors along with poor flows of information and resources. Such conditions are ripe for creating poor perceptions of clarity in relation to their patients, and hence likely to affect nurses' ability to service patients efficiently and effectively. Therefore, this area needs further research.

Using the LMX lens, the ideal situation is when all employees experience high quality supervisor-subordinate relationships because this will deliver the greatest benefits to both the individual and the organisation. High quality LMX is associated with increased information, resources and support - supervisors allocate increased organisational resources (time and respect) towards each subordinate, resulting in empowering relationships for subordinates (Gerstner \& Day, 1997; Sparrowe \& Linden, 1997). This framework provides an excellent lens for comparing the impact of public and private sector supervision practices on nurses' perceptions of patient role clarity and their subsequent perceptions of autonomy and job satisfaction. The following primary research questions therefore guide the data collection:

PRQ1: What is the impact of the supervisor-subordinate relationship upon nurses' perceptions of patient role clarity, autonomy and job satisfaction?

PRQ2: Is the impact of the supervisor-subordinate relationship the same upon public and private sector nurses' perceptions of patient role clarity, autonomy and job satisfaction?

\section{Supervisor-Subordinate Relationship}

The LMX concept is useful to examine within the public sector because, as stated, recent reforms were specifically aimed to curb the power of public sector employees by increasing their accountability (Ackroyd et al., 2007). Hoggett (1994) argues that for professionals (such as nurse supervisors), the strategy has not been to directly control nurses. Instead, it has been to convert nurse supervisors into managers and place the responsibility for achieving organisational goals (typically "doing more with less") on them. 
As a consequence, nurses in the UK, USA, NZ and Australian public sectors have experienced a standardisation in the delivery of service, with resultant work intensification (Ackroyd, et al., 2007; Willis, Toffoli, Henderson \& Walter, 2008). In particular, public sector nurses have experienced increased workloads, poorer working conditions, inflexible scheduling, increased intensity of work, loss of work autonomy and increased accountability (Newman, Maylor \& Chansarkar, 2002; Wong, 2004). This extra pressure for nurses to perform is escalating, leading to lower morale and job satisfaction, plus higher turnover (Chan, 2001). Concurring, Rankin (2010) argued the need for nurses to join together to tackle issues arising from nursing being too focussed on healthcare efficiencies, while Allen (2004) argued that contemporary nursing's main contribution is merely healthcare mediation. However in the public sector, because of the performance indicators imposed on them by management, supervisors have had to invoke their managerial power and increase nurses' levels of accountability (Butterfield, et al., 2005). The outcome for nurse managers has been the conflicting expectations of creating empowering social environments while simultaneously operating within "tight budgetary controls and performance measures and targets" (Bolton, 2003, p. 126). These new conditions may have negatively affected the supervisor-nurse relationship for public sector nurses. However, it is unclear whether nurses in the private sector are working within similar supervisory environments. Because the supervisor-nurse relationship in the public sector has changed, it is expected that public sector nurses now experience lower levels of satisfaction with their supervisors compared with private sector nurses. This area requires further examination.

\section{Role clarity in relation to patients}

Public sector nurses experience high role clarity (the equivalent of low role ambiguity) in relation to patients when they know what the patient needs and they have the information, resources and support needed to address those needs within the broader organisational, policy 
and legal framework (Johlke \& Duhan, 2000). In practice, high patient role clarity means that nurses have embedded high quality social networks to easily find information and resources when needed. Patient role clarity issues do not arise so much in attending to patients with routine problems. Instead, role ambiguity is far more likely when a patient presents with complicated circumstances (such as when a surgical patient demonstrates signs of severe irrationality). In these cases, research suggests that employees with less experience rely heavily on their effective workplace social networks (such as with supervisors) to assist them to make better workplace decisions (Johlke \& Duhan, 2000; Rhoads, Singh \& Goodell, 1994). Research also suggests that the relationship with the supervisor often provides the cornerstone of effective workplace networks (Johlke \& Duhan, 2000; Rhoads, et al., 1994). When nurses are clear about their role expectations (having sufficient and relevant information, resources and support), then they are likely to experience role clarity in relation to patients. However, without effective workplace relationships to aid in determining how to address the needs of patients, nurses may experience role ambiguity. Yet, patient role ambiguity can also stem from changing traditional practices that are taken for granted (Parker, 2004). Thus, role ambiguity is also likely for nurses in the private sector, where business models and profit-making drive efficiency measures that may be similar to the public sector. Hence, while there is an association between role clarity and relationships with supervisors for the public sector, it is unclear whether similar associations exist for nurses in the private sector. The following hypothesis tests this proposition:

H1: Public and private sector nurses' satisfaction with their supervisor-subordinate relationships is positively related to their patient role clarity.

\section{Autonomy}

Although Larsen (2005) argues that developing nursing skills and knowledge continues to be a battleground, nurses have power and autonomy because of these attributes. Carrington (2005) concurs, noting that public sector nurses have autonomy because laws cannot anticipate 
all potential problems and consequences, yet governments perceive such power as a problem because those with such power remain unaccountable to the electorate. However, nurses cannot do their job without autonomy because attending to numerous patients involves making choices about the quality and quantity of resources spent (Riccucci, 2005).

The concept of 'discretionary power' or autonomy in the public sector literature is conceptualised as 'empowerment' within the management literature. Spreitzer (2007) identifies two conceptualisations of empowerment: structural (whether the organisational structures and processes facilitate optimal employee performance) and psychological (employees' responses and outcomes from working within a particular organisational empowerment context). Kanter's (1977) theory of structural empowerment proposes that organisations determine the quality of structural empowerment experienced by employees by influencing access to resources, information, guidance and support. This thereby determines how much power an employee has. Hence, Seibert, Silver and Randolph (2004) argue that the quality of structural empowerment is evident in employees' perceptions of psychological empowerment.

Further, supervision practices have been identified as a major determinant of employees' perceptions of autonomy (Gagne \& Deci, 2005). Using LMX theory, because nurses in high quality LMX relationships would have adequate information, resources and trust to solve problems be empowered to make decisions, and work in an environment embedded with mutual respect, it is expected that the higher their perceptions of patient role clarity, the higher their perceptions of autonomy. However, it is argued that because of the changes to public sector supervision practices, private sector nurses are likely to have higher perceptions of autonomy, patient role clarity and resultant higher levels of autonomy and job satisfaction, compared with public sector nurses. It remains unclear whether nurses in the two sectors experience similar perceptions, and therefore the following hypothesis tests this proposition:

H2: Public and private sector nurses' perceptions of patient role clarity are positively related to their perceptions of autonomy. 


\section{Job satisfaction}

Job satisfaction refers to the extent to which employees gain enjoyment from their efforts at the workplace and the attitude of an individual about his/her job (Fogarty 1994). Job satisfaction is often examined in organisational studies because it is a predictor of other organisational outcomes, such as job productivity (Goris, Vaught \& Pettit, 2000; Petty, McGee \& Cavender, 1998) and retention (Cowin, 2002). Previous research suggests that nurse's level of job satisfaction is dependent on a mix of intrinsic (such as their desire to help people) and extrinsic (such as organisational policies and practices) factors (Newman, et al., 2002). Similarly, for nurses in particular, other researchers have evidence that job satisfaction as a function of management style, autonomy, pay, professional status, good interpersonal relationships (interaction), task requirements and effectiveness of organisation policies and practices (Adams \& Bond, 2000; Best \& Thurston, 2004). While there is a significant relationship between employees' perception of autonomy and job satisfaction, it is unclear whether the relationship is similar for public and private sector nurses. This is examined in the following hypothesis:

H3: Public and private sector nurses' perceptions of autonomy positively affect their job satisfaction.

Similarly, the relationship between public and private sector nurses' levels of satisfaction with their supervisor-nurse practices, perceptions of patient role clarity, autonomy and job satisfaction is unclear. To address this void, the following hypothesis is examined:

H4: Public and private sector nurses' perceptions of patient role clarity, autonomy and satisfaction with their supervisor-subordinate relationship positively affect their job satisfaction.

\section{Nurses in the public and private sector}


Australia's healthcare system comprises public, private and not-for-profit sectors. The public sector of Australian healthcare provides approximately 60 percent of hospital beds and the combined private and non-profit sectors provide $40 \%$ (Gee, 2007). There are similarities across the sectors and many nurses undertake comparable clinical work especially because public-private partnerships have partially blurred the public-private sector divide (Brown \& Barnett, 2004). Consequently, some private hospitals provide services to public patients because of specific contracts in place and vice versa. However, this does not mean that management practices within public hospitals are the same as those in private and/or non profit hospitals. Steane (1997) argues that the differences in core values associated with the different sectors drive subtle differences in management practices. Hence, supervision practices are likely to differ in public hospitals compared with private and non-profit hospitals.

However, the increases in formal hierarchical authority in the public sector due to the changes in public sector management have probably impacted more in that sector than in the private sector (Ferlie, et al. 1996; Kirkpatrick \& Ackroyd, 2003). While the quality of nurses' supervisor-nurse relationships, perceptions of patient role clarity, perceptions of autonomy and in turn, their job satisfaction have probably impacted more upon the public sector than upon the private sector, it is unclear whether public and private sector nurses have similar experiences. However, it is expected that public sector nurses will have more negative consequences. To examine this premise, the following hypothesis is proposed:

H5: Private sector nurses experience higher levels of satisfaction with supervisor-nurse relationships, patient role clarity, autonomy and job satisfaction compared with public sector nurses.

\section{METHODS}

This research used embedded mixed methods to gather primary quantitative and secondary qualitative data (Creswell \& Plano-Clark, 2007) to compare the relationships between 
supervisor-subordinate relationships, autonomy, patient role clarity and job satisfaction for both public and private sector nurses. Following ethics approval from the university's human research ethics committee and all hospitals involved, the primary quantitative date was collected to examine whether such relationships exist, while the secondary qualitative data was collected to confirm (or not) the primary data results and further understand the role of patient role clarity and its association with job satisfaction. For the quantitative data collection, a cross-sectional design was used to test whether the quality of relationships between public and private sector nurses and their supervisors affects their perceptions of patient role clarity and autonomy and in turn, their job satisfaction.

An anonymous survey-based, self-report strategy was used (Ghauri \& Gronhaug, 2002) and informed consent of the respondents was obtained for each respondent. Surveys were distributed to most wards within each of the participating hospitals and nurses were encouraged by their management to anonymously complete the survey and return it in the reply-paid envelopes to the researchers. The emerging patterns of data were then compared with the findings of previous research. Survey data were collected from nurses working in either public or private hospitals in Australia during 2007 and 2008. Confidentiality was assured via a cover note attached to the survey explaining the rationale and process of the research.

The secondary qualitative data were collected from focus groups of typically 5 nurses to further examine what factors affect patient role clarity from the perspective of nurses. The format of the focus groups was that demographic details were taken first, followed by discussions about patient role clarity/clarity in the workplace. The focus groups were audiotaped while field notes were also taken and were conducted within the various hospitals. Participants were sought from the same hospitals as for the primary quantitative data. Participation was voluntary and the sessions, lasting 45 to 75 minutes, were commonly conducted during change-over periods between shifts. 


\section{Measures}

The survey measures were generated from the extant literature and presented using statements to be rated on a 6 -point Likert-type scale, with $1=$ strongly disagree, ranging to $6=$ strongly agree. Satisfaction of nurses with the quality of their supervisor-subordinate relationship was measured using a seven-item uni-dimensional scale (LMX-7), developed by Graen and Uhl-Bien (1995), including, 'My NUM knows how good I am at my job'. Perception of autonomy was operationalised using Spreitzer's (1995) three-item measure of selfdetermination because it has the strongest correlation to organisational effectiveness, including, 'I can decide on my own how to go about doing my work'. Role clarity was measured using 3 items of Johlke and Duhan's (2000) instrument, including 'I am certain of what I am expected to do for my patients'. Job Satisfaction was measured using 4 items of Johlke and Duhan's (2000) instrument, including 'I feel that my job is satisfying'.

The focus groups were designed around understanding nurses' perceptions of the factors that they perceived as impacting upon the clarity of their role in relation to their patients, understanding their patients' needs and the resources, information and support needed to address those needs. Open discussion centred on these issues.

\section{Samples}

The samples included public and private sector nurses from four states across Australia, working in either public or private small ( $<300$ beds), medium $(300-500$ beds) or large $(>500$ beds) hospitals, and in both rural and urban locations. The 3 public hospitals comprised 1 large, medium and small hospital, while the 7 private hospitals comprised 4 small, 2 medium and 1 large hospitals. To gather quantitative data from nurses, 4,800 anonymous surveys were distributed. The response rate for the public sector was $29.6 \%$ and for the private sector was 22.5\%. A total of 1138 useable surveys was received, equating to an overall response rate of approximately $24 \%$. 
The focus group sample comprised those nurses who agreed to participate further in this research either by direct contact with the researchers or via their nurse manager.

\section{Analysis of the data}

Path analysis was used to test the primary quantitative data in terms of the impact of supervisor-nurse relationship upon firstly, nurses' perceptions of role clarity, secondly, upon autonomy and thirdly, job satisfaction. In particular, path analysis using an ordinary least square (OLS) approach was used to test the model. OLS is an explanation of variance and the overall $\mathrm{R}^{2}$ measure identifies the overall goodness of fit for the proposed model (Ahn, 2002). The advantage of path analysis is that it permits more than one equation to predict the dependent variable (job satisfaction) and therefore it includes the indirect impact of supervisor-nurse relationship into the bigger equation. The OLS approach also estimates parameters within an independent system, which could avoid the problem of multicollinearity (Grapentine, 2000).

For the qualitative data, the tape-recorded data were transcribed and categorised based on 'commonalities and differences' across emerging themes and then frequencies for each category were determined (Ghauri \& Gronhaug, 2002). The systematic patterns that emerged were used to draw conclusions to support (or not) the primary quantitative data

\section{RESULTS}

\section{Results from quantitative analysis}

Table 1 shows that the public sector nurse sample comprised $90(37.8 \%)$ males and 148 $(62.2 \%)$ females $(\mathrm{N}=238)$ and the private sector nurse sample comprised $33(3.7 \%)$ males and $867(96.3 \%)$ females $(\mathrm{N}=900)$. Average age groups ranged from under 30 years $(10 \%), 30-45$ years $(40 \%)$ to over 45 years $(50 \%)$. Within the public sector nursing sample, 52 were Nurse Unit Managers (NUM), 60 were senior clinical nurses, 101 were Registered Nurses (RN), and 18 were Enrolled Nurses (EN) and 7 were Assistants in Nursing (AIS). Within the private sector 
nursing sample, 55 were Nurse Unit Managers (NUM), 112 were senior clinical nurses, 626 were Registered Nurses (RN), and 103 were Enrolled Nurses (EN) and 4 were Assistants in Nursing (AIS). The sample is therefore representative of the Australian nursing demographic, where $40 \%$ are aged 45 years or older, and nearly $90 \%$ are qualified nursing professionals (ABS 2005), however, there were more males in the public sector sample $(37.8 \%)$ than is typical for Australia (9\%).

\section{[Insert Table 1 here]}

\section{Exploratory Factor Analysis}

The correlation matrix identified many correlations exceeding .3, indicating the matrix was suitable for factoring. The Bartlett's test for Sphericity was significant (Chi-square value $=8262.806, \mathrm{p}<.001$. df 66) and the Kaiser-Meyer-Olkin (KMO) measure of sampling adequacy was .848 - well above the .6 requirement. When Principal Axis Factoring was undertaken to extract the variables, four factors had eigenvalues greater than one and $75.755 \%$ of the variance could be explained using these four factors. The factor transformation matrix suggests a relatively high correlation between factors. As stated, the advantage of using an OLS approach can avoid the problem of multicollinearity.

\section{Correlation Matrix}

Table 2 details the correlation coefficients for each variable. All variables were significantly related to one another except for the control variable - location. The Cronbach's alpha coefficients measuring reliability ranged from 0.89 to 0.93 .

\section{[Insert Table 2 here]}

To address the first hypothesis (Public and private sector nurses' satisfaction with their supervisor-subordinate relationships is positively related to their patient role clarity), a regression analysis was undertaken and the findings suggest that the hypothesis is supported (See Table 3). Public sector nurses' satisfaction with their supervisor-nurse relationship 
accounted for $22.2 \%$ of their perceptions of patient role clarity. Private sector nurses' satisfaction with their supervisor-nurse relationships accounted for $6.8 \%$ of their perceptions of patient role clarity. This means that over a fifth of the variance of public sector nurses' perceptions of patient role clarity can be accounted for by satisfaction with their supervisor/nurse relationships. In contrast, it accounted for only $6.8 \%$ for private sector nurses. Secondly, the correlation findings indicate that the higher the level of satisfaction with supervisor-nurse relationships, the greater the patient clarity for nurses. Moreover, from Table 2, the combined nurses' mean for satisfaction with supervisor-nurse relationships (4.61 of 6) suggests that, on average, the nurses are nearly satisfied. The mean for role clarity (5.4 of 6) suggests that nurses agreed that they had role clarity in relation to their patients, supporting the hypothesis further.

[Insert Table 3 here]

To address the second hypothesis (Public and private sector nurses' perceptions of patient role clarity are positively related to their perceptions of autonomy), a regression analysis was undertaken and the findings suggest that the hypothesis is supported (see Table 4). Private sector nurses' perceptions of patient role clarity account for less than half $(2.1 \%)$ that of public sector nurses' perceptions of autonomy. Public sector nurses' perceptions of patient role clarity account for $4.3 \%$ of their perceptions of autonomy. This means that less than 5 percent of the variance of either public and private sector nurses' perceptions of autonomy can be accounted for by their perceptions of patient role clarity. While the correlation is significant, the findings suggest that perceptions of patient role clarity contribute minimally to nurses' perceptions of autonomy. Secondly, the findings indicate that the greater the perceptions of patient role clarity, the greater the perceptions of autonomy, supporting the hypothesis.

[Insert Table 4 here] 
To address the third hypothesis (Public and private sector nurses' perceptions of autonomy positively affect their job satisfaction), a regression analysis was undertaken and the findings suggest that the hypothesis is supported (See Table 5). Private sector nurses' perceptions of autonomy account for $13.6 \%$ of the variance explaining their perceptions of job satisfaction. Public sector nurses' perceptions of autonomy account for $6.5 \%$ of the variance explaining their perceptions of job satisfaction. This means that perceptions of autonomy contribute more in explaining the variance for private sector nurses', compared with public sector nurses' levels of job satisfaction. Nevertheless, the findings suggest that for all the nurses, the higher the perceptions of autonomy, the greater the resultant levels of job satisfaction.

[Insert Table 5 here]

To address the fourth hypothesis (Public and private sector nurses' perceptions of patient role clarity, autonomy and satisfaction with their supervisor-subordinate relationship positively affect their job satisfaction), path analysis using an ordinary least square (OLS) approach was used and the findings suggest that the hypothesis is supported. Supervisor-nurse relationship, patient role clarity and autonomy account for $30.7 \%$ of the variance explaining private sector nurses' levels of job satisfaction. Supervisor-nurse relationships, patient role clarity and autonomy account for $11.9 \%$ of the variance explaining public sector nurses' levels of job satisfaction. This means that these same variables account for varying degrees of job satisfaction. One explanation is that management practices are indeed different across private and public sector hospitals (see Table 6).

\section{[Insert Table 6 here]}

To address the fifth hypothesis (Private sector nurses experience higher levels of satisfaction with supervisor-nurse relationships, patient role clarity, autonomy and job satisfaction, compared with public sector nurses), an independent t-test was undertaken and the 
findings suggest that the hypothesis is supported. The findings indicate that there are significant differences in the levels of satisfaction of supervisor-nurse relationships, patient role clarity, autonomy and job satisfaction between public and private sector nurses. In addition, there was a significant difference in the age composition of the samples, suggesting that age may be a contributing factor to explain some of the differences found between samples (see Table 7).

[Insert Table 7 here]

\section{Results from Qualitative Analysis}

A total of 137 (75 public and 62 private sector) nurses comprised this secondary data set sample. Females comprised $88 \%$ of this overall sample, while males comprised $12 \%$ (see Table 8 for details). The overall sample was dominated by nurses aged 30-45 years (53\%) compared to those aged more than 45 years (28\%) and those aged less than 30 years (20\%). However, between the two sectors, there were more nurses over the age of 30 years in the public sector than there was in the private sector. That is, on average, the public sector sample was older than the private sector sample.

\section{[Insert Table 8 here]}

Based on the qualitative data, frequencies of commonalities were identified between the nurses' perceptions and opinions. The systematic patterns that emerged were used to draw conclusions to support (or not) the primary quantitative data (See Tables 9 and 10). Thematic analysis of the qualitative data supports the quantitative results, suggesting that both public and private sector nurses' perceptions of patient role clarity are strongly determined by their workplace relationships, including their supervisors, but also their peers. The dominant themes (judged as frequencies of 5 or more) that emerged from the public sector nurses comprised 3 positive (good teamwork, good resources and good training) and 4 negative (poor skills mix, nurse shortage, poor resources plus poor clinical leadership and management) themes. The 
dominant themes from the private sector sample comprised 4 positive (good management and teamwork, good support, good working environment and flexibility meeting patient needs) and 3 negative (high workloads, poor skills mix and poor management/communication) themes.

In summary for nurses, management practices generally, and the actions of supervisors particularly, appeared to be critical to perceptions of their ability to meet patients' needs. The most frequent positive themes for both groups concerned workplace relationships and teamwork as being central to nurses' role clarity. Access to an appropriate skills mix on the ward, to resources, support and information plus training are reported by nurses in both sectors as affecting their perceptions about whether they can meet their patients' needs. In contrast, negative themes for both groups were linked to perceptions of inadequate resourcing and poor management. High workloads and a shortage of nurses clearly exacerbates such perceptions.

[Insert Tables 9 and 10 here]

\section{DISCUSSION}

This paper compared four important health management issues: supervisor-subordinate relationships, patient role clarity, plus perceptions of autonomy and job satisfaction, between public and private sector nurses. Public and private sector nurses' levels of satisfaction with supervisor-nurse relationships were compared first; both groups identified that they were at least slightly satisfied, although private sector nurses were more satisfied than public sector nurses. Satisfaction with supervisor-nurse relationships is important because past research has identified these relationships affect the retention of nurses (Cohen, 2006) and those reporting dissatisfaction are more likely to leave (Gray \& Phillips, 1994; Secombe \& Smith, 1997). Further, the results suggest that supervisor-nurse relationships significantly predict almost a quarter of public sector nurses' patient role clarity, and 6.8 percent for private sector nurses, concurring with past public sector research by Johlke and Duhan (2000) and Rhoads et al. 
(1994). In addition, these findings suggest that working environments differ significantly between public and private sector nurses.

We next compared public and private sector nurses' perceptions of role clarity in relation to patients. Both public and private sector nurses identified that they experienced patient role clarity (the opposite of role ambiguity). One explanation for this is that public sector reforms place a heavy focus on servicing the patient. Another explanation is that nurses have always been technically apt at addressing the needs of patients. However, in both cases, public and private sector nurses' high perceptions of patient role clarity contributed very little to their perceptions of autonomy. Other factors not examined in this paper are clearly more important in determining nurses' autonomy in the workplace. Examining autonomy more closely, public sector researchers (such as Ackroyd et al., 2007) identified the likely lower perceptions of autonomy by public sector employees and this was confirmed in our findings. However, even the private sector nurses appeared to feel only slightly autonomous, although this was significantly more than public sector nurses.

Individually, autonomy predicted 14 percent of job satisfaction for private sector nurses, and using path analysis, the findings suggest that these factors accounted for almost a third of the variance explaining job satisfaction (see Figure 1). In addition, the results of the independent t-test suggest significant differences in means for each factor. Notably, the qualitative research findings confirmed the importance of supervisor-nurse relationships in affecting job satisfaction, suggesting that while public and private sector nurses may attend to the same type of patients (Brown and Barnett, 2004), the work context in which they operate varies significantly. In particular, nurses experienced different supervisor-subordinate relationships, different perceptions of patient role clarity and autonomy and consequently, significantly different levels of job satisfaction.

\section{Limitations}


The main limitation of this study is the use of self-report surveys potentially causing common methods bias. However, Spector (1994) argues that self-reporting methods is legitimate for gathering data about employees' perceptions, as long the instrument reflects an extensive literature review, pattern-matching is used to support interpretations of the data and triangulation is used to support research findings. Further, to reduce common method bias when the criterion and predictor variable cannot be measured in different contexts, as in this study, Podsakoff, Mackenzie, Lee and Podsokoff (2003) recommend separating the measurement of the criterion and predictor variables psychologically and ensuring the survey is anonymous. The survey applied these recommendations. Another limitation is that there was a significant difference in the age of the two survey samples with the public sector nurses being significantly younger. Further studies exploring the impact of age in these circumstances may be worthwhile, because past research has identified differences in workforce participation based on generational cohorts (Crumpacker \& Crumpacker, 2007) possibly affecting the development of effective supervisor-subordinate relationships.

\section{Implications}

The implications of the findings include new knowledge of similarities and differences for public and private sector nurses about how (less than ideal) supervision (negatively) affects their perceptions of patient role clarity, autonomy and in turn, job satisfaction. As such, this paper contributes to the wider contemporary debate about the importance of improving organisational processes affecting supervisor-subordinate relationships, and nurses' perceptions of patient role clarity, autonomy and in turn, job satisfaction. However, both groups of nurses were only somewhat satisfied with their supervision. While that may or may not be related to increases in managerial autonomy, it does suggest that the present state of workplace relationships between supervisors and nurses is not contributing to a free flow of resources and information and/or facilitating reciprocal trusting-empowering work contexts that would be ideal for empowering the nurses and also addressing the needs of patients. Because past research has 
already established a significant positive relationship between the quality of supervisorsubordinate relationships and organisational effectiveness (Gerstner \& Day, 1997), it seems unlikely that the present conditions are ideal for achieving organisational effectiveness in these public hospitals. Worse, these conditions appear less than optimum for retention and high turnover is expensive because nurses are university qualified and highly-trained. Additionally, they are in high demand throughout most OECD countries, making retention even more crucial to organisational effectiveness and quality patient outcomes.

Of the two groups, private sector nurses were the most satisfied with their supervision, and reported some level of autonomy and job satisfaction. However, the means for both groups suggest that both public and private sector nurses appear to operate in work contexts that are frustrating for them and these organisational conditions are unlikely to improve job satisfaction. Because job satisfaction is a predictor of turnover (Petty, et al., 1998), these findings challenge the worth of pursuing current management reform practices negatively impacting upon supervisor-nurse relationships, in turn affecting other processes. These reforms were expected to deliver efficiency gains for the public sector; however, the proponents of such policies are silent in identifying the cost of these policies in terms of public sector nurses' low levels of satisfaction with organisational processes.

\section{CONCLUSION}

Nursing is facing shortages in many countries globally, and effective retention strategies are in high demand. Using the LMX lens, this study revealed the current situation of supervisornurse relationships in some hospitals in Australia, and the resultant perceptions of patient role clarity, autonomy and job satisfaction of their nurses. The findings indicate that present management practices are not ideal for promoting the very workplace relationships needed to support effective work processes to achieve successful nurse and patient outcomes. One lesson for health management must be to ensure the development of high quality, supportive and 
empowering relationships between nurse supervisors and their nurses. For all nurses, not only will they be more productive when they experience high quality supervision (comprising information- and resource-sharing as well as participatory decision-making), but these same conditions will also enhance their perceptions of patient role clarity, autonomy and job satisfaction and therefore are also likely to encourage them to stay.

The findings of the study are important for (particularly public sector) healthcare researchers and managers because, as Ackroyd et al. (2007, p. 23) argue, there has been little attempt by government to 'evaluate whether management reforms ... actually work' for all stakeholders concerned. While the success of reforms has probably been affected by numerous factors, it seems likely that if the reforms have been successful, there would be adequate nurses to deliver the public service. Hence, a comparison of public and private sector nurses' attitudes towards management practices may shed new light on what needs to change, to keep nurses satisfied with their job, and entice them to remain. Therefore, the findings contribute to the wider contemporary debate about the importance of improving organisational processes affecting supervisor-subordinate relationships and autonomy if the needs of patients are to be addressed. 


\section{REFERENCES}

Ackroyd, S., Kirkpatrick, I., \& Walker, R. (2007). Public management reform in the UK and its consequences for professional organization: A comparative analysis. Public Administration, 85(1), 9-26.

Adams, A., \& Bond, S. (2000). Hospital nurses' job satisfaction, individual and organisational characteristics. Journal of Advanced Nursing, 32(3), 536-543.

Ahn, J. (2002). Beyond single equation regression analysis: Path analysis and multi-stage regression analysis. American Journal of Pharmaceutical Education, 66, 37-42.

Allen, D. (2004). Re-reading nursing and re-writing practice: towards an empirically based reformulation of the nursing mandate. Nursing Inquiry, 11(4), 271 - 283.

Basu, R., \& Green, S. G. (1995). Subordinate performance, leader-subordinate compatibility, and exchange quality in leader-member dyads: A field study. Journal of Applied Social Psychology, 25(1), 77-92.

Behn, R. (2002). The psychological barriers to performance management or why isn't everyone jumping on the performance management bandwagon? Public Performance and Management Review, 26(1), 5-25.

Best, M., \& Thurston, N. E. (2004). Measuring job satisfaction. Journal of Nursing Administration, 34(6), 283-290.

Bolton, S. (2003). Multiple roles? Nurses as managers in the NHS. International Journal of Public Sector Management, 16(2), 122-130.

Brown, L., \& Barnett, J. (2004). Is the corporate transformation of hospitals creating a new hybrid healthcare space? Social Science Medicine, 58(2), 427-444.

Butterfield, R., Edwards, C., \& Woodall, J. (2005). The new public management and managerial roles: The case of the police sergeant. British Journal of Management, 16, 219-341.

Carrington, K. (2005). Street level discretion: is there for a need for control? Public Administrative Quarterly, 29(1/2), 139-163.

Chan, C.-P. (2001). Implications of organizational learning for nursing managers from the cultural, interpersonal and systems thinking perspectives. Nursing Inquiry, 8(3), 196-199.

Cohen, J. (2006). The aging nursing workforce: How to retain experienced nurses Journal of Healthcare Management, 51(4), 233- 246.

Cowin, L. (2002). The effects of nurses' job satisfaction on retention. Journal of Nursing Administration, 32(5), 283-291.

Creswell, J. W., \& Plano Clark, V. L. (2007). Designing and conducting mixed methods research. Thousand Oaks: Sage Publications. 
Crumpacker, M., \& Crumpacker, J. (2007). Successful planning and generational stereotypes: Should HR consider age-based values and attitudes a relevant factor or a passing fad? Public Personnel Management 36(4), 349-369.

Currie, G., \& Procter, S. (2002). The interaction of human resource policies and practices with the implementation of teamworking: Evidence from the UK public sector. The International Journal of Human Resource Management 14(4), 581-599.

Ferlie, E., Pettigrew, A., Ashburner, L., \& Fitzgerald, L. (1996). The New Public Management in Action. Oxford: Oxford University Press.

Gagne, M., \& Deci, E. L. (2005). Self-determination theory and work motivation. Journal of Organizational Behavior, 26, 331-362.

Gee, C. (2007). The Contribution of the Australian Private Sector Hospitals Sector. Asian Pacific Journal of Health Management, 2(1), 41-46.

Gerstner, C., \& Day, D. (1997). Meta-analytic review of leader-member exchange theory: Correlates and construct issues. Journal of Applied Psychology, 82, 827-844.

Ghauri, P., \& Grønhaug, K. (2002). Research methods in business studies: A practical guide (2nd ed.). Harlow, UK: Financial Times Prentice Hall.

Goris, J., Vaught, B., \& Pettit, J. (2000). Effects of communication direction on job performance and satisfaction: A moderated regression analysis. Journal of Business Communication, 37(4), 348-368.

Graen, G., \& Uhl-Bien, M. (1995). Relationship-based approach to leadership: Development of leader-member exchange (LMX) theory of theory over 25 years: Applying a multi-level multi-domain perspective. Leadership Quarterly, 6(2), 219-247.

Grapentine, T. (2000). Path analysis vs. structural equation modeling. Marketing Research,, 12(3), 13-20.

Gray, A., \& Phillips, V. (1994). Turnover, age and length of service: A comparison of nurses and other staff in the National Health Service Journal of Advanced Nursing 19(4), 819827.

Hawthorne, L. (2001). The globalisation of the nursing workforce: barriers confronting overseas qualified nurses in Australia. Nursing Inquiry, 8(4), 213 - 229.

Hoggett, P. (1994). The politics of the modernisation of the UK welfare state. In R. Burrows \& G. Holmes (Eds.), Towards a Post-Fordist Welfare State? . London: Routledge.

Hoque, K., Davis, S., \& Humphries, M. (2004). Freedom to do what you are told: Senior management's autonomy in an NHS Acute Trust. Public Administration, 82(2), 355-376.

Johlke, M. C., \& Duhan, D. F. (2000). Supervisor communication practices and service employee job outcomes. Journal of Service Research, 3(2), 154-165. 
Kanter, R. (1977). Men and women of the corporation. New York: Basic Books.

Kelly, J. (2005). The dilemma of the unsatisfied customer in a market model of public administration. Public Administration Review, 65(1), 76-84.

Kingma, M. (2001). Nursing migration: global treasure hunt or disaster-in-the-making? Nursing Inquiry, 8(4), 205-212.

Kirkpatrick, I., \& Ackroyd, S. (2003). Transforming the professional archetype? The new managerialism in UK social services. Public Management Review, 5(4), 511-531.

Larsen, A.-C. (2005). In the public interest: autonomy and resistance to methods of standardising nurses' advice and practices from a health call centre in Perth, Western Australia. Nursing Inquiry, 12(2), 135-143.

Newman, K., Maylor, U., \& Chansarkar, B. (2002). The nurse satisfaction. Service quality and nurse retention chain: Implications for management of recruitment and retention. Journal of Management in Medicine, 16(4/5), 271-292.

OECD. (2005). Ageing and employment policies - Australia. Paris: Organisation for Economic Cooperation and Development.

Parker, J. M. (2004). Nursing on the medical ward. Nursing Inquiry, 11(4), 210 - 217.

Petty, M., McGee, G., \& Cavender, J. (1998). A meta-analysis of the relationships between individual performance. Academy of Management Review 9(4), 712-721

Podsakoff, P. M., MacKenzie, S. B., Lee, J.-Y., \& Podsakoff, N. P. (2003). Common method biases in behavioral research: A critical review of the literature and recommended remedies. Journal of Applied Psychology, 88(5), 879-903.

Podsakoff, P. M., MacKenzie, S. B., Paine, J. B., \& Bachrach, D. G. (2000). Organizational citizenship behaviors: A critical review of the theoretical and empirical literature and suggestions for future research. Journal of Management, 26(3), 513-563.

Rankin, J. M. (2010). The Nurse Project: an analysis for nurses to take back our work. Nursing Inquiry, 16(4), 275-286.

Rhoads, G. K., Singh, J., \& Goodell, P. W. (1994). The multiple dimensions of role ambiguity and their impact upon psychological and behavioural outcomes of industrial salespeople. Journal of Personal Selling and Sales Management 14, 1-22.

Riccucci, N. M. (2005). Street-level bureaucrats and intrastate variation in the implementation of temporary assistance for needy families policies. Journal of Public Administration Research and Theory, 15(1), 89-111.

Secombe, I., \& Smith, G. (1997). Taking part: Registered nurses and the labour market in 1997. Grantham, England: Grantham Book Services. 
Seibert, S., Silver, S., \& Randolph, W. (2004). Taking empowerment to the next level: A multiple-level model of empowerment, performance, and satisfaction. Academy of Management Journal, 47, 332-349.

Sparrowe, R., \& Linden, R. (1997). Process and structure in leader-member exchange. Academy of Management Journal, 22(2), 522-552.

Spector, P. E. (1994). Using self-reported questionnaires in OB research: A comment on the use of a controversial method. Journal of Organisational Behavior, 15(5), 385-392.

Spreitzer, G. (1995). Psychological empowerment in the workplace: Dimensions, Measurement and Validation. Academy of Management Journal, 38(5), 1442-1465.

Spreitzer, G. (1996). Social Structural Characteristics of Psychological Empowerment. Academy of Management Journal, 39(2), 483-504.

Spreitzer, G. (2007). Taking stock: A review of more than twenty years of research on empowerment at work. In C. Cooper \& J. Barling (Eds.), The handbook of organizational behaviour. Thousand Oaks, CA.: Sage Publications.

Steane, P. (1997). Oils Ain’t Oils! Strategy Across Sectors. International Journal of Public Sector Management, 10, 461-470.

Tregunno, D., Peters, S., Campbell, H., \& Gordon, S. (2009). International nurse migration: Uturn for safe workplace transition. Nursing Inquiry, 1(3), 182-190.

Wayne, S., Shore, L., \& Linden, R. (1997). Perceived organisational support and leader exchange: A social exchange perspective. Academy of Management Journal, 40(1), 82111.

Willis, E., Toffoli, L., Henderson, J., \& Walter, B. (2008). Enterprise bargaining: a case study in the de-intensification of nursing work in Australia. Nursing Inquiry, 15(2), 148-157.

Winch, S., Creedy, D., \& Chaboyer, W. (2002). Governing nursing conduct: the rise of evidence-based practice. Nursing Inquiry, 9 (3), 156 - 161.

Wong, W. H. (2004). Caring holistically within new managerialism. Nursing Inquiry, 11(1), 213.

Yrie, A., Hartman, S., \& Galle, W. (2003). Examining communication style and leader-member exchange: considerations and concerns for managers. International Journal of Management 20(1), 92-100.

Yukl, G. (2006). Leadership in organizations (6th ed.). Upper Saddle River, NJ: PearsonPrentice Hall. 


\section{TABLES}

Table 1: Demographics of the quantitative sample

\begin{tabular}{lccc}
\hline & $\begin{array}{c}\text { Public sector } \\
\text { nurses } \\
(\mathrm{N}=238)\end{array}$ & $\begin{array}{c}\text { Private sector } \\
\text { nurses } \\
\end{array}$ & $\begin{array}{c}\text { TOTAL } \\
(\mathrm{N}=1138)\end{array}$ \\
\hline SEX: & & & \\
Male & $90(38 \%)$ & $33(3.7 \%)$ & $123(10.8 \%)$ \\
Female & $148(62.5 \%)$ & $867(96.2 \%)$ & $1015(89.2 \%)$ \\
AGE: & & & \\
$<30$ years & $41(17.3 \%)$ & $74(8.2 \%)$ & $115(10.1 \%)$ \\
$30-45$ years & $114(47.7 \%)$ & $339(37.7 \%)$ & $453(39.8 \%)$ \\
$>45$ years & $83(35 \%)$ & $487(54.1 \%)$ & $570(50.1 \%)$ \\
& & & \\
\hline
\end{tabular}

Table 2: Means, standard deviations, correlations and Cronbach's alpha coefficients

\begin{tabular}{llllllll}
\hline Variable & Mean & SD & $\mathbf{1}$ & $\mathbf{2}$ & $\mathbf{3}$ & $\mathbf{4}$ & $\mathbf{5}$ \\
1. Location (control) & & & 1 & & & & \\
2. Supervisor-nurse r'ship & 4.61 & 1.15 & -.04 & 1 & $\mathbf{( . 9 3 )}$ & & \\
3. Patient role clarity & 5.4 & .77 & -.04 & $.37 * *$ & 1 & $\mathbf{( . 9 1 )}$ & \\
4. Autonomy & 4.29 & 1.01 & .02 & $.26 * *$ & $.23 * *$ & 1 & $\mathbf{( . 9 0 )}$ \\
5. Job Satisfaction & 4.92 & .81 & .03 & $.41^{* *}$ & $.24 * *$ & $.35^{*}$ & $1(\mathbf{. 8 9})$ \\
\hline N = 1138. Numbers in parentheses on the diagonal are the Cronbach alpha coefficients of the composite scales.
\end{tabular}

Table 3: Regression analysis detailing supervisor-nurse relationship as a predictor of patient role clarity

\begin{tabular}{lcc}
\hline Patient role clarity & Private sector nurses & Public sector nurses \\
& $\beta$ & $\beta$ \\
Supervisor-nurse relationship & $.26^{* *}$ & $.47^{*}$ \\
F & $65.58^{* *}$ & $66.42^{* *}$ \\
$\mathbf{R}^{2}$ & $\mathbf{. 0 6 8}$ & $\mathbf{. 2 2}$ \\
$* *$ Correlation is significant at the 0.01 level (2-tailed). & \\
$*$ Correlation is significant at the 0.05 level (2-tailed). &
\end{tabular}


Table 4: Regression analysis detailing patient role clarity as a predictor of nurses' perceptions of autonomy

\begin{tabular}{lcc}
\hline Perceptions of autonomy & Private sector & Public sector \\
& $\beta$ & $\beta$ \\
Patient role clarity & $.14^{* *}$ & $.21^{* *}$ \\
F & $19.13^{* *}$ & $20.43^{* *}$ \\
$\mathbf{R}^{2}$ & $\mathbf{. 0 2 1}$ & $\mathbf{. 0 4 3}$ \\
\hline
\end{tabular}

** Correlation is significant at the 0.01 level (2-tailed).

Table 5: Regression analysis detailing nurses' perceptions of autonomy as a predictor of job satisfaction

\begin{tabular}{lcc}
\hline $\begin{array}{l}\text { Perceptions of } \\
\text { Autonomy }\end{array}$ & Private sector nurses & Public sector nurses \\
Job satisfaction & $\beta$ & $\beta$ \\
F & $.37^{* *}$ & $.26^{* *}$ \\
& $141.37^{* *}$ & $16.50^{* *}$ \\
$\mathbf{R}^{2}$ & $\mathbf{. 1 3 6}$ & $\mathbf{. 0 6 5}$ \\
$*$ Correlation is significant at the 0.01 level (2-tailed). &
\end{tabular}

Table 6: Regression analysis detailing supervisor-nurse relationship, patient role clarity and autonomy as predictors of job satisfaction

\begin{tabular}{lcc}
\hline Job satisfaction & Private sector nurses & \multicolumn{2}{c}{ Public sector nurses } \\
& $\beta$ & $\beta$ \\
Superv-nurse r'ship & $.36^{* *}$ & $.25^{* *}$ \\
Patient role clarity & $.16^{* *}$ & -.04 \\
Perceptions of autonomy & $.25^{* *}$ & $.23^{* *}$ \\
F & $131.44^{* *}$ & $26.42^{* *}$ \\
$\mathbf{R}^{2}$ & $\mathbf{. 3 0 7}$ & $\mathbf{. 1 1 9}$ \\
* Correlation is significant at the 0.01 level (2-tailed).
\end{tabular}


Table 7: Independent Samples Test: Public and Private sector nurses

\begin{tabular}{|c|c|c|c|c|c|}
\hline & \multicolumn{2}{|c|}{ Private sector $^{\#}$} & \multicolumn{2}{|c|}{ Public sector $^{\# \#}$} & \multirow[b]{2}{*}{ T value } \\
\hline & $\operatorname{Mean}^{a}$ & $\overline{\text { SD }}$ & $\overline{\operatorname{Mean}^{a}}$ & SD & \\
\hline Age $(1=<30 \mathrm{yrs}, 2=30-45 \mathrm{yrs}, 3=>45 \mathrm{yrs})$ & 2.46 & 0.64 & 2.18 & 0.7 & $5.80 * *$ \\
\hline Satisf. with superv-nurse r'ship & 4.72 & 1.08 & 4.19 & 1.3 & $5.62 * *$ \\
\hline Patient role clarity & 5.64 & 0.54 & 4.81 & 0.95 & $17.40 * *$ \\
\hline Autonomy & 4.39 & 0.97 & 3.94 & 1.08 & $3.76^{* *}$ \\
\hline Job satisfaction & 1.96 & 0.76 & 4.79 & 1.09 & $2.40 * *$ \\
\hline
\end{tabular}

\# $\mathrm{N}=900 \quad$ \#\# $\mathrm{N}=238$

${ }^{\mathrm{a}}$ Mean: $1=$ Strongly Disagree, through to $6=$ Strongly Agree

** Correlation is significant at the 0.001 level (2-tailed).

Table 8: Demographics of the focus groups

\begin{tabular}{lccc}
\hline & $\begin{array}{c}\text { Public sector } \\
\text { nurses } \\
(\mathbf{N}=\mathbf{7 5})\end{array}$ & $\begin{array}{c}\text { Private sector } \\
\text { nurses } \\
(\mathbf{N}=\mathbf{6 2})\end{array}$ & TOTAL \\
\hline SEX: & $8(10.7 \%)$ & $9(14.5 \%)$ & $17(12.4 \%)$ \\
Male & $67(89.3 \%)$ & $53(85.5 \%)$ & $120(87.6 \%)$ \\
Female & & & \\
& & & \\
AGE: & $10(13.3 \%)$ & $17(27.4 \%)$ & $27(19.7 \%)$ \\
<30 years & $45(60 \%)$ & $27(43.5 \%)$ & $72(52.6)$ \\
30 $\mathbf{4 5}$ years & $20(26.7 \%)$ & $18(29 \%)$ & $38(27.8 \%)$ \\
$>$ 45 years & & & \\
& & & \\
\hline
\end{tabular}


Table 9: Public sector nurses: Factors affecting patient role clarity ${ }^{\#}$

\begin{tabular}{|l|c|l|c|}
\hline \multicolumn{1}{|c|}{ Positive Themes } & Frequency & \multicolumn{1}{|c|}{ Negative Themes } & Frequency \\
\hline $\begin{array}{l}\text { Effective Teamwork and } \\
\text { good collegial } \\
\text { relationships including } \\
\text { with the NUM (everyone } \\
\text { helps get the work done) }\end{array}$ & 47 & $\begin{array}{l}\text { Poor skills mix } \\
\text { (Lack of experienced nurses who } \\
\text { can deal with a range of } \\
\text { complications) }\end{array}$ & 21 \\
\hline $\begin{array}{l}\text { Good resources } \\
\text { Good training }\end{array}$ & 7 & $\begin{array}{l}\text { Nurse shortage (Not enough time } \\
\text { for complicated cases) }\end{array}$ & 18 \\
\hline $\begin{array}{l}\text { Respect for nursing role } \\
\text { (by medical practitioners } \\
\text { and allied health healthcare } \\
\text { practitioners) }\end{array}$ & 3 & $\begin{array}{l}\text { Poor level of resources } \\
\text { (Lack of wards men, good working } \\
\text { equipment - both basic and } \\
\text { specialist) }\end{array}$ & 13 \\
\hline $\begin{array}{l}\text { Flexibility in meeting } \\
\text { needs of patient }\end{array}$ & 1 & $\begin{array}{l}\text { Poor clinical leadership and } \\
\text { management, poor reporting lines } \\
\text { and communication }\end{array}$ & 3 \\
\hline \begin{tabular}{l} 
Good leadership \\
\hline
\end{tabular} & 1 & $\begin{array}{l}\text { Poor flexibility in meeting needs of } \\
\text { patients }\end{array}$ & 2 \\
\hline
\end{tabular}

${ }^{\#} \mathbf{N}=75$

Table 10: Private sector nurses: Factors affecting patient role clarity ${ }^{\#}$

\begin{tabular}{|l|c|l|c|}
\hline \multicolumn{1}{|c|}{ Positive Themes } & Frequency & \multicolumn{1}{|c|}{ Negative Themes } & Frequency* \\
\hline $\begin{array}{l}\text { Good management and } \\
\text { effective teamwork }\end{array}$ & 33 & $\begin{array}{l}\text { High patient nurse ratio -high } \\
\text { workloads }\end{array}$ & 9 \\
\hline $\begin{array}{l}\text { Having support when you } \\
\text { need it }\end{array}$ & 17 & Poor skills mix & 7 \\
\hline $\begin{array}{l}\text { Having a good working } \\
\text { environment }\end{array}$ & 7 & $\begin{array}{l}\text { Bad management and poor } \\
\text { communication }\end{array}$ & 2 \\
\hline $\begin{array}{l}\text { Flexibility in meeting needs } \\
\text { of patient }\end{array}$ & 5 & Poor training & 5 \\
\hline
\end{tabular}

${ }^{\#} \mathrm{~N}=62$

* Please note that some nurses did not identify negative factors 


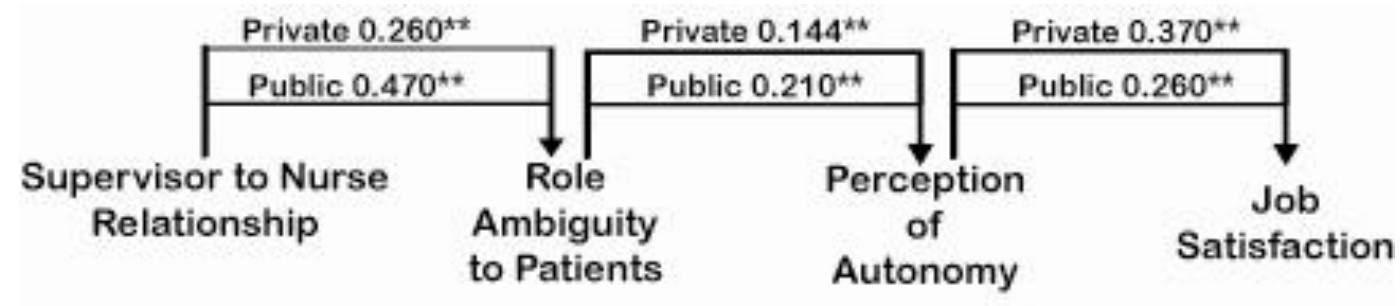

Public Sector Nurses $\left(R^{2}\right)=11.9 \%$

Private Sector Nurses $\left(R^{2}\right)=30.69 \%$

Figure 1: The relationship between supervisor-nurse relationship, patient role clarity, perceptions of autonomy and job satisfaction of nurses 